Politische Bildung heute

Unterrichtsbeispiele aus der Schulpraxis 


\title{
Politische Bildung heute
}

Unterrichtsbeispiele aus der Schulpraxis

\author{
Herausgegeben \\ im Auftrag der Deutschen Vereinigung \\ für politische Bildung
}

Springer Fachmedien Wiesbaden GmbH 1967 
Redaktionelle Bearbeitung: Dr. Walter Gagel

ISBN 978-3-663-12316-3

ISBN 978-3-663-12315-6 (eBook)

DOI 10.1007/978-3-663-12315-6

Verlags-Nr. 19001

(C) 1967 by Springer Fachmedien Wiesbaden

Ursprünglich erschienen bei C. W. Leske Verlag, Opladen in 1967

Gesamtherstellung: Dr. Friedrich Middelhauve GmbH, Opladen Umschlagentwurf: Klaus Winterhager 


\section{Vorbemerkung}

Die auf der Tagung der Deutschen Vereinigung für politische Bildung in Berlin am 13. 10. 1965 vorgetragenen Unterrichtsmodelle sind von den Verfassern für die Drucklegung überarbeitet worden. Zur Vereinheitlichung des Druckbildes und zur Vermeidung von Wiederholungen wurden die Beiträge von der Redaktion des Bandes durch Kürzungen und Einfügung von $Z$ wischen- oder Untertiteln z. T. geringfügig verändert. Wir hoffen, dem Leser hierdurch gedient zu haben.

W. G. 


\section{Inhalt}

Vorbemerkung $\ldots \ldots \ldots \ldots \ldots \ldots \ldots \ldots \ldots \ldots \ldots \ldots \ldots$

Dr. Friedrich Minssen

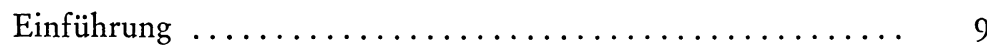

Adalbert Brunner

unter Mitarbeit von Dr. Walter Jabn

Das Erscheinungsbild des Totalitarismus in der Sowjetunion.... 25

Dr. Wilbelm Gall

Die Militärgewalt des Staates als Problem der politischen

Bildungs- und Erziehungsarbeit in der Höheren Schule ...... 40

Dr. Lore Obrt

Grundlegende Veränderungen im Bereich der bäuerlichen

Familie und des Dorfverbandes und ihre Beziehungen zur

Stadt-Land-Polarität ...................... 56

Hans Ritscher

Das Problem der gerechten Vermögensverteilung $\ldots \ldots \ldots \ldots \quad 90$

Dr. Wolfgang Haseloff

Die deutsche Landwirtschaft und der Gemeinsame Markt . . . . 114

Hans-Georg Hartmann

Soziale Partnerschaft ................... 144 
Dr. Walter Gagel

Das Problem der innerparteilichen Demokratie ......... 156

Dr. Kurt Fackiner

Die Selbstreflexion gesellschaftlicher Positionen als

didaktisches Prinzip des politischen Unterrichts dargestellt an

einem Unterrichtsversuch über die politischen Parteien

in der Gemeinschaftskunde .................... 176

Die Autoren dieses Buches ..................... 197 